\title{
Long-Term Effects of Stimulant Treatment for ADHD: What Can We Tell Our Patients?
}

\author{
Stephanie G. Craig • Gregory Davies • Larry Schibuk • \\ Margaret D. Weiss $\cdot$ Lily Hechtman
}

Published online: 30 January 2015

(C) Springer International Publishing Switzerland 2015

\begin{abstract}
Introduction Stimulant medication is a well-researched treatment for attention deficit hyperactivity disorder (ADHD) and is among the most effective treatments in psychiatry. Parents often want to know more about the long-term risks and benefits of medication. Our objective was to review the seminal papers on long-term outcomes of stimulant treatment for ADHD for the purpose of providing clinicians with the background they need to interpret these findings for patients.

Methods We reviewed key articles on long-term outcome of symptoms, comorbidity, substance use, executive functioning, academics, side effects, neurobiology, functioning, and quality of life.

Results Stimulants are very effective medications in the short term when used optimally. Long-term randomized, placebocontrolled studies are not feasible. Long-term naturalistic studies are limited by absence of controls.
\end{abstract}

This article is part of the Topical Collection on $A D H D$

\section{S. G. Craig}

Simon Fraser University, Burnaby, Canada

S. G. Craig • G. Davies $・$ L. Schibuk • M. D. Weiss

Weiss ADHD Care, Vancouver, Canada

G. Davies

Community Living BC, Vancouver, Canada

M. D. Weiss $(\square)$

University of British Columbia, Vancouver, Canada

e-mail: margaret.weiss@icloud.com

L. Hechtman

Division of Child Psychiatry, McGill University, Montreal, Canada

L. Hechtman

Psychiatry ADHD Clinic, Montreal Children's Hospital, McGill

University Health Centre, Montreal, Canada
Discussion When administered properly with careful titration, follow-up, and dose adjustment, stimulants are a safe and effective treatment for ADHD with minimal long-term risk and possible long-term benefit.

Keywords ADHD $\cdot$ Stimulant medication . Long-term effect $\cdot$ Outcome

\section{Introduction}

Clinicians routinely have to summarize the risks and benefits of stimulant medication to their patients. Parents are often as concerned about whether stimulants will have any long-term beneficial or detrimental effects, as they are about the immediate effects of medication. The clinician is often in the position of having to address parents' questions about the longterm risk and benefit of medication. For example, parents may assume that if their child is performing better in the classroom now, this will increase the chances that they will show greater academic achievement in the long term. Parents are also often concerned about possible invisible long-term effects of psychotropic medication on brain health. This has been an anathema as long as clinicians have been using stimulant medication for ADHD in children. Can we assume that the often dramatic, immediate response we see when stimulants are initiated predicts a better outcome in adulthood?

Currently, there is a wealth of research on the use of stimulant medication for the treatment of attention deficit hyperactivity disorder (ADHD) with the most prominent study being the NIMH Collaborative Multisite Multimodal Treatment Study of Children With Attention-Deficit/Hyperactivity Disorder (MTA; [1]). The MTA compared four distinct treatment strategies (i.e. medication, behavioural treatment, combination medication and behavioural treatment and community care) as part of a randomized control study (RCT) of 579 
children diagnosed with ADHD as per the DSM-IV. At the end of the randomized trial (14 months), a local normal control group was added and all patients were followed prospectively. We have ample evidence of short-term efficacy [2, 3], but sparse evidence of long-term effectiveness.

There are a number of limitations to consider when exploring the long-term effects of medication for the treatment of ADHD. Very few patients stay on medication for the duration of the study; for example, the MTA found that at the 8-year follow-up, only $32.5 \%$ of the participants were medicated at least $50 \%$ of the days in the previous year [1] and only $10 \%$ were on medication at the 16-year follow-up (personal communication, Lily Hechtman). There may be a selection bias towards patients with more severe impairment opting to continue medication, therefore limiting the conclusions that can be drawn from naturalistic follow-up studies. In addition, naturalistic studies follow patients who are being seen in the community and whose outcome may be less favourable than would be found in expert care, as demonstrated in the MTA [1].

It is possible that for some patients, medication facilitates the acquisition of executive function skills, but current research suggests that new skills may also be facilitated by training (organizational skills training [4], cognitive behaviour therapy [5]) with or without use of medication. The common adage 'pills do not teach skills' implies that just as it may be possible to teach new skills even in the absence of medication treatment, use of medication alone cannot be assumed to lead to new habits. With these limitations in mind, our objective here is to review the seminal papers on long-term outcomes of stimulant treatment for ADHD in children and to formulate an evidence-based, patient friendly statement regarding longterm outcomes of stimulant medication.

\section{Methods}

Using PsycINFO, Google Scholar, and Medline search engines and using the terms long term, outcome, stimulant, ADHD, and treatment, we identified articles that examined and reviewed the long-term impact of stimulant medication on various aspects of functioning. Key search terms such as neurobiological changes and academic performance were added following the initial search. This is not a comprehensive review of long-term outcome studies of which there are several $[6 \bullet \bullet, 7 \bullet, 8]$. We have selected salient studies on each outcome to determine the state of the art at this point of time. Prominent articles were chosen based on their unique contribution to our understanding of long-term impacts and their frequency in reviews. Our selection of outcome variables was limited to those outcomes for which evidence is currently available. For the purposes of this review, short-term outcome was defined as less than 4 months, intermediate outcome as between 4 and 12 months, and long-term outcome as anything more than 1 year.

\section{Symptom Reduction}

Studies examining symptom reduction have found a beneficial effect for stimulant medication in the reduction of ADHD symptoms. This finding has been consistent across the literature and found to be specifically related to the continued use of medication and medication adherence [2,9]. We can assert with confidence that stimulants are efficacious for symptoms of ADHD in the randomized double-blind placebo-controlled trials in short- and intermediate-term studies [10].

The MTA extended the robust literature on the efficacy of short-term stimulant for select patient populations to longerterm effectiveness outcomes in a more naturalistic sample. There is evidence that assignment to a medication treatment arm continued to confer some additional benefit after randomization was discontinued for up to 3 years [11]. After 3 years, the effects of the 14-month randomization were no longer evident. The MTA study at the 8-year follow-up found that the improvement found in symptoms was sustained [1], even though the selective benefit of randomization to medication was not longer evident.

While we know that stimulants are a very effective treatment during the period in which they are prescribed, they are often understood as like 'glasses for the brain' rather than a 'cure'. Other strategies such as learning adaptive skills or restructuring the social environment to be ADHD friendly may also mitigate impairment from symptoms, and again, these effects would likely endure for as long as the coping strategies remain in place. Stimulants are not an absolute requirement for a good outcome, nor do they guarantee a good outcome in individual cases. These are drugs that for the most part offer control of symptoms for the period of time that the drug is administered at an effective dose.

\section{Comorbidity}

There is also a growing interest in the effect of stimulant medication on comorbid conditions such as depression, anxiety and disruptive disorders. One study has found that stimulant medication protects against later risk for depressive, disruptive and anxiety disorders [12]. The MTA study found higher rates of delinquency in children who were prescribed medication at the 36-month follow-up; however, the relationship between medication and delinquency was unclear [13]. Other studies have shown associated negative emotional or mood side effects with a delayed onset that may not be evident until up to 4 months after starting treatment $[14,15]$. Although stimulants can have negative psychiatric side effects (e.g. 
blunted affect), it is important to distinguish between side effects and psychiatric comorbid symptoms as ADHD itself is a risk factor for comorbid anxiety and depressive symptoms.

Stimulants may both mitigate and/or be a cause of side effects that look like comorbid psychopathology in individual children. This can depend on the nature of the comorbid symptoms (such as blunted affect, dysphoric mood, irritable mood), the individual risk profile of the child and the nature of the treatment. It is possible that stimulants lower the risk for later comorbidity [12]; however, one consideration is that there is a possible selection bias towards children with low risk for comorbidity being less likely to be treated with stimulant medication. Parents are perhaps best advised to be vigilant that the effects of stimulants may have an impact on non ADHD symptoms, both for the better (a protective effect on the emergence of comorbid conditions) or for the worse (treatment emergent psychiatric side effects). This is not an inconsequential recommendation. All too often, parents may fail to report changes in affect or cognition, because they do not understand that a medication can have both psychiatric and somatic side effects.

\section{Substance Abuse}

There were concerns in the past over whether treatment of ADHD with a controlled substance might increase the risk for future substance abuse. Wilens et al. suggested that on the contrary, the use of stimulants in childhood might actually decrease the risk of future drug and alcohol use disorders [16, 17]. Other, more recent studies have continued to show that stimulants might have a protective effect in mitigating the risk for later substance abuse [18]. However, the evidence on whether stimulants decrease the risk for later substance abuse is inconsistent. The MTA study found that medication did not protect from, contribute to, or create a risk for substance use or substance use disorders in adolescence [19]. Although there is evidence to suggest either no effect or a possible protective effect of stimulant medication, there continues to be concern regarding the risk of use of stimulant medication in youth who are already engaging in some substance use [20].

The clinician can reassure families that there is no ground for the concern that the use of a controlled medication will somehow prime the brain or increase the risk for later substance addiction. It has become commonplace for clinicians to go further and state that stimulants have been shown to protect against later substance abuse. The evidence for a protective effect of stimulant treatment on later substance abuse is inconsistent. At this point in time, we may be able to tell parents that there is some evidence to suggest that stimulants may have a protective effect against future substance abuse.

\section{Executive Functioning and Organization}

There is little research on the long-term effects of stimulant medication on executive functions in patients with ADHD. The lack of data on short-term efficacy of medication for these difficulties is striking, particularly in the face of robust data on the efficacy of treatment in adults with or without medication [21] and for children who receive organizational skills training [4]. Some cross-sectional research has found improved executive function in children with ADHD-Combined type during the period of medication treatment $[22,23]$. In fact, the first well-controlled studies of immediate, short-term effects of stimulants on executive functions as an outcome are only emerging recently [24]. The data for executive function outcomes in long-term studies is negligible. This gap in the literature is concerning given the high association between problems in executive functioning and ADHD $[25,26]$ and our understanding that work habits are highly predictive of adult outcome.

Increased awareness of the clinical importance of executive function as an umbrella concept and more specific target areas subsumed awareness, such as organization, has made it clear that we need to know more about whether stimulants facilitate acquisition or maintenance of organizational skills. There is one double-blind randomized controlled study (DBRCT) to say that stimulants are efficacious in the treatment of executive functions. There is also now more than one study suggesting that psychosocial treatments are also effective treatments for executive dysfunction, whether or not stimulants are present $[21,5]$.

Stimulants alone may improve executive function and/or organization in some patients, while additional training in these skills is required for other patients. Some patients may improve with training in organizational skills, regardless of whether they have responded to stimulants or can take stimulants. Organizational skills training (with or without medication) is an evidence-based and highly effective treatment for organization deficits [4]. Abikoff and Hechtman did not find the addition of behavioural treatments to medication predicted better outcome [27, 28]. However, medication in this study was very carefully monitored and adjusted on a monthly basis for 2 years and the families were very high functioning and so may have provided additional interventions themselves.

Patients may want to know whether stimulants will improve specific targets such as working memory, time management, or organization in the long term. They may also want to know whether state-dependent acquisition of organization skills while on medication will translate into an enduring trait. We do not have evidence to support the idea that the acquisition of these skills at the time of treatment will be generalized to how the patient functions off medication. However, the absence of evidence does not mean that early treatment benefit does not translate into changes that do endure. 


\section{Academic Outcomes}

Stimulant medication has been shown to have a robust effect on academic performance in school, but there is very limited evidence to suggest that stimulants have a direct or clinically meaningful effect on achievement. Hechtman and Abikoff studied long-term academic outcome in children treated with well-titrated and monitored medication, alone, in addition to multimodal psychosocial treatment, or an attention control. Although in this study, there was no placebo group, the fact that all three groups had equal and very substantial academic improvement suggests that medication as administered in this study may have had an impact on academic achievement during the time it is given [28, 29]. Stimulants have been described as improving test-taking ability (e.g. improved concentration), homework completion, productivity, listening, note taking and handwriting. There is population data suggesting that earlier start of stimulants mitigates the decline in math achievement associated with ADHD [30]. The effect of stimulants on academic performance in school is often described as an improvement in a student's ability 'to show what they know', as opposed to an improvement in the potential for learning per se.

Scheffler and colleagues [31] found that the typical trajectory of achievement over a 5-year period produced gains equivalent to .19 school years for math and .29 school years for reading. These were robust statistical findings, but their clinical significance is less clear. It is hard to make the case that a gain of the equivalent of 1 to 4 months of schooling, after years of medication treatment, is clinically significant. Furthermore, the data from retrospective case control studies does not support this finding. Some studies have failed to find an association between stimulant treatment and academic achievement outcome [32].

The long-term follow-up of the MTA found that only math achievement was higher, and not reading achievement, academic performance or grade point performance, at the 8-year follow-up point. However, they also note that there was a maintenance of the initial overall achievement scores for all treatment groups [1] independent of whether or not they had been assigned to a treatment that included medication. This would seem to suggest that it is not so much medication itself, but whether or not there is an early improvement in academics that is mediating the long-term academic outcome. This may be significant in that it is now much more common to mitigate the performance difficulties of children with ADHD with accommodations such as increased time on tests, or use of computer technologies.

All of these studies may suffer from referral bias. It is unclear whether the families that elected to use medication were more concerned about academic achievement and therefore more motivated to provide academic remediation in addition to stimulant treatment. It is also possible that there could be selection bias in the direction that children at risk for academic failure were more likely to receive stimulant medication. Lastly, if selection bias was acting in both a positive and negative direction, the mediating effects of the circumstances by which parents elect to use stimulants treatment would mask our potential to identify unique effects of medication itself.

In understanding this literature, there is one finding that appears consistent across multiple studies. It seems reasonable to assume that improved academic performance during the years that a child takes stimulant medication would improve academic achievement as an adult. It is not clear that this is the case. Even those studies that do demonstrate sleeper effects of improved academic performance on stimulants show very modest gains on later academic achievement. This may, perhaps, explain why some of the adults with ADHD that we see clinically are remarkably knowledgeable, even in the face of school failure. It is rare to see this level of disparity between knowledge and academic credentials in other populations.

The best that can be said at this point in time is that stimulants appear to help academic performance although the impact on ultimate academic achievement is less clear. Clinicians can suggest to parents that stimulants are quite likely to lead to an improvement in school performance as measured for example by grades. While it would appear reasonable to assume that early academic gains would translate into meaningful long-term academic success, this is less evident at this point in time. Methodological limitations make research into the question of whether stimulants improve the likelihood of a university degree or other markers of academic achievement known to be predictive of better employment. A final consideration is that other accommodations (e.g. individualized education plans) may be required to remediate other skills and learning in addition to appropriate levels of medication.

\section{Side Effects and Growth}

Studies have generally focused on short-term side effects (e.g. delayed sleep, reduced appetite, headaches, weight loss) with the initiation of medication, rather than on long-term effects. Of the long-term studies that have been conducted, few studies have commented on side effects [33]. In a 5-year study, Charach et al. [34] found the most common side effect to be loss of appetite and at least one physiological side effect (e.g. headache, abdominal pain) was reported by at least half of the participants. However, they found that children continued to use medication despite these side effects, suggesting a mild effect.

The relationship between stimulant medication use and growth rates is inconsistent. Early studies suggested that long-term use of high doses of stimulant medication over time has measureable effects on the rate of growth [14]. Some authors have found that some of this dysregulation of growth may be mediated by the ADHD rather than its treatment [14, 
$35,36]$. Other studies have failed to show the same effect in adults with ADHD who had been followed since childhood $[37,38]$ and in population-based studies [14]. Open label follow-up studies of stimulant medications have shown growth deceleration, and when it does occur, it appears to be minimal and most common in the first or second year of treatment and then levelling off [39-42]. Likewise, the MTA found that the initial difference in height and weight in year 1 to be absent by year 3 in the study $[11,43]$. Nonetheless, the MTA did demonstrate a consistent difference in height attainment in those who had received stimulants and those who had not. More important, there was a direct dose effect of stimulant exposure and growth deceleration. The conclusions from these studies, and from reviews of these studies, are inconsistent. Apart from the MTA, these studies also do not control for total stimulant exposure.

We can say that both ADHD and stimulants are associated with difficulty sleeping and eating, which may in turn impact growth. While there is some evidence that stimulants are associated with growth deceleration, this has not been confirmed across different study designs, or other methodological procedures. Even in the face of a small risk of growth deceleration, it remains good clinical practice to follow the growth trajectory of each child. This is particularly true for children who are already growth challenged by virtue of being small for gestational age, foetal alcohol syndrome or other factors.

\section{Neurobiological Effects}

Research from imaging studies suggest that subjects with ADHD who have received therapeutic doses of medication show attenuation of structural and functional changes that are otherwise seen in unmedicated subjects and controls. For example, cross-sectional MRI studies have found psychostimulant medication treatment to be associated with the normalization of posterior inferior cerebellar vermis [44], white matter normalization [45], right ACC normalization [46], subtle attenuation of reduced splenium volume [47] and attenuation of basal ganglia surface deformations [48].

One longitudinal study found that psychostimulants were associated with the slowing of overall growth of the cortical mantle over a 4-year period [49]. This study has since been replicated, and meta-analytic reviews support the idea that stimulants may have a neuro-protective effect [50,51]. The evidence that stimulants protect against cortical thinning is intriguing, but the immediate clinical effects of this finding are not clear.

\section{Quality of Life}

Quality of life outcomes are difficult to assess, especially since quality of life is an umbrella construct for health, emotional well-being, life satisfaction and social functioning [52]. In ADHD, the findings on quality of life are complicated by the fact that many studies rely on parent report, which is a proxy for quality of life as measured by the child. This is further complicated by a lack of agreement between parent and child reports of quality of life [53, 54]. In addition, children with ADHD may have a positive illusory bias $[55,56]$, which may compromise the validity of self-report by children on their own quality of life. It is clear that ADHD has a profound effect on the quality of life of children - comparable to major medical conditions such as diabetes or asthma [52, 57]. There is also evidence that stimulant treatment mitigates the negative impact of ADHD on quality of life [58-61] during the course of short- and intermediate-term treatment. Whether this is related to a direct effect of the medication itself or remediation of symptoms that might occur with other treatment modalities is unclear [62].

Given the difficulties in assessing quality of life, qualitative analyses may provide insight into patient's subjective perception. In one qualitative analysis, Charach et al. [63] found that adolescents on medication were able to complete school work, have increased self-confidence and decreased conflict at home which they identified as positive effects. However, they also found a negative effect on the youth's sense of self with youth reporting that they no longer felt like themselves, were happier off the medication and noticed a change in their personalities. These answers are important to consider, as they effect both the adolescent's decision to continue medication and risk for developing future mental health concerns. Conversely, in a systematic review, Shaw and colleagues [7•] found an increase in self-esteem and social functioning when outcomes were dichotomized to either positive or negative.

Patients may benefit from understanding that stimulant medication will improve the well-being of children as well as their ADHD symptoms. This being said, we do not know that this improvement in quality of life while on stimulant endures later in development. Common sense would suggest that better quality of life as a child would have an enduring impact. Yet again, however, methodological constraints will likely make it difficult to demonstrate this empirically.

\section{Functioning}

In one of the few studies to examine functional impairment in a long-term outcome study, Fuentes and colleagues [64] found both stimulant medication and atomoxetine to be associated with persistent and stable improvements in functional impairment as measured by the Weiss Functional Impairment Rating Scale-Parent over a 1-year period. The best data on longterm outcomes of functional impairment after stimulant discontinuation comes from the MTA. There was no relative advantage of stimulant treatment over other treatments at 
3 years. There was evidence that early improvement for all treatment conditions predicted continued benefit in the long term [65]. At the 8-year follow-up, although gains were maintained, overall functioning remained significantly lower for the MTA youth relative to the local normative comparison group [1].

For academic, quality of life and functional outcomes, it would appear that early improvement, whether from stimulant treatment or other factors, predicts later benefit.

\section{Discussion}

Consistent with other research [66॰], this review found that there are a very limited number of high-quality studies on the long-term outcome of stimulants [66 $]$. Methodological problems make it difficult to obtain any randomized or even controlled data over an extended period of time [1]. RCT trials are by definition short term for both reasons of ethics and feasibility. Naturalistic prospective studies that look at the association between early stimulant treatment and later adult outcomes are limited by referral bias, lack of a control and other methodological problems. Naturalistic studies provide information on associations, but cannot be used to infer cause. The issue of long-term impact of medication beyond 2 years [28], and especially after discontinuation of medication, may not be a researchable question.

A fair interpretation of what we can tell patients at this point in time must include a clear understanding that absence of evidence is not evident of absence. What we do know is that stimulant medication used optimally is a safe and effective treatment for up to 2 years [28]. We also know that while for the most part, the literature described above does not demonstrate a selective longterm advantage of stimulant medication, early benefit and improvement did predict later improvement [67].

One main concern when reviewing literature on longterm outcomes is that there is considerable inconsistency in how long researchers consider short-, intermediate- or long-term outcome to be [66•]. 'Long-term' has been defined in this paper as over a year; however, in the literature, the definition can range from 12 weeks [6••] to 10 years [12]. In addition, most studies of long-term stimulant outcome up to this point have examined the ADHD-Combined type population as diagnosed by previous versions of the Diagnostic and Statistical Manual. Very few, if any studies, examined the impact of medication for children with ADHD-Inattentive type or sluggish cognitive tempo [68]. Research has also failed to consider contextual and cultural differences, such as North American versus European or Asian populations $[66 \bullet]$.
There is also inconsistency in what is meant by stimulant treatment. The outcomes of Medication Management and Community Care in the MTA were as different as combined treatment and behavioural treatment. Both the medication management and $66 \%$ of the patients treated in the community received medication, but the community group did not do well since medication was poorly given in the community group. In the community group, there was no careful titration to optimal dose with parent and teacher input and no ongoing monitoring once every 2 to 3 months to see if dose adjustment was needed to optimize benefits and decrease side effects. Furthermore, we do not know whether the long duration stimulants might have a greater long-term impact than the immediate release stimulants. Open label follow-up studies of new stimulant formulations, while not randomized, do suggest that stimulants do continue to exert comparable effects at 1 and 2 years of outcome as they did in randomized studies. Given that long-term persistence with stimulant medication is less than $50 \%$, the most clinically relevant question is whether the robust immediate effects of these medications when they are prescribed have an enduring benefit down the road if they are discontinued. We can for the most part answer this question by saying we do not know. While we cannot promise parents that stimulant treatment will make a long-term difference, it is also important to point out that this is a very high bar for measuring medication effectiveness. We would not ask, for example, if immediate treatment of asthma would prevent recurrence in adulthood.

In the absence of a feasible and sound research design that can address the question of whether stimulants have enduring effects many years later, particularly when medication has been discontinued, this information therefore is likely to remain elusive. We can inform our patients that stimulant medication when used according to best practices is a safe and effective treatment for ADHD, as are non-medication interventions. Medication is effective as long as it is taken and properly titrated, monitored and adjusted. With or without medication, many patients also benefit from skills training (social skills, organizational skills), and these also may need to be implemented in an ongoing fashion. Early improvement in functioning in its own right may be a predictor of longer-term gains suggesting that successful early intervention has a long-term benefit however it is obtained.

\section{Compliance with Ethics Guidelines}

Conflict of Interest Stephanie G. Craig, Gregory Davies, Larry Schibuk, Margaret D. Weiss and Lily Hechtman declare that they have no conflict of interest.

Human and Animal Rights and Informed Consent This article does not contain any studies with human or animal subjects performed by any of the authors. 


\section{References}

Papers of particular interest, published recently, have been highlighted as:

- Of importance

•- Of major importance

1. Molina BS, Hinshaw SP, Swanson JM, Arnold LE, Vitiello B, Jensen PS, et al. The MTA at 8 years: prospective follow-up of children treated for combined-type ADHD in a multisite study. J Am Acad Child Adolesc Psychiatry. 2009;48(5):484-500.

2. Spencer T, Biederman J, Wilens T, Harding M, O'Donnell D, Griffin S. Pharmacotherapy of attention-deficit hyperactivity disorder across the life cycle. J Am Acad Child Adolesc Psychiatry. 1996;35(4):409-32 [see comments].

3. Garland EJ. Pharmacotherapy of adolescent attention deficit hyperactivity disorder: challenges, choices and caveats. J Psychopharmacol. 1998;12(4):385-95.

4. Abikoff H, Gallagher R, Wells KC, Murray DW, Huang L, Lu F, et al. Remediating organizational functioning in children with ADHD: immediate and long-term effects from a randomized controlled trial. J Consult Clin Psychol. 2013;81(1):113-28.

5. Solanto MV, Marks DJ, Wasserstein J, Mitchell K, Abikoff H, Alvir $\mathrm{JM}$, et al. Efficacy of meta-cognitive therapy for adult ADHD. Am J Psychiatry. 2010;167(8):958-68.

6.• Maia CRM, Cortese S, Caye A, Deakin TK, Polanczyke GV, Polanczyk CA, et al. Long-term efficacy of methylphenidate immediate-release for the treatment of childhood ADHD: a systematic review and meta-analysis. J Atten Disor. 2014. This is the most recent meta-analysis of the long-term effectiveness of methylphenidate treatment of $A D H D$.

7. Shaw M, Hodgkins P, Caci H, Young S, Kahle J, Woods AG, et al. A systematic review and analysis of long-term outcomes in attention deficit hyperactivity disorder: effects of treatment and nontreatment. BMC Med. 2012;10:99. A review of treatment vs. nontreatment in 351 long-term outcome studies suggesting that treatment improves long-term functioning.

8. Spencer TJ, Brown A, Seidman LJ, Valera EM, Makris N, Lomedico A, et al. Effect of psychostimulants on brain structure and function in ADHD: a qualitative literature review of magnetic resonance imaging-based neuroimaging studies. J Clin Psychiatry. 2013;74(9):902-17.

9. Charach A, Ickowicz A, Schachar R. Stimulant treatment over five years: adherence, effectiveness, and adverse effects. J Am Acad Child Adolesc Psychiatry. 2004;43(5):559-67.

10. Gillberg C, Melander H, von Knorring AL, Janols LO, Thernlund $\mathrm{G}$, Hagglof B, et al. Long-term stimulant treatment of children with attention-deficit hyperactivity disorder symptoms. A randomized, double-blind, placebo-controlled trial. Arch Gen Psychiatry. 1997;54(9):857-64.

11. Murray DW, Arnold LE, Swanson J, Wells K, Burns K, Jensen P, et al. A clinical review of outcomes of the multimodal treatment study of children with attention-deficit/hyperactivity disorder (MTA). Curr Psychiatry Rep. 2008;10(5):424-31.

12. Biederman J, Monuteaux MC, Spencer T, Wilens TE, Faraone SV. Do stimulants protect against psychiatric disorders in youth with ADHD? A 10-year follow-up study. Pediatrics. 2009;124(1):71-8.

13. Molina BS, Flory K, Hinshaw SP, Greiner AR, Arnold LE, Swanson JM, et al. Delinquent behavior and emerging substance use in the MTA at 36 months: prevalence, course, and treatment effects. J Am Acad Child Adolesc Psychiatry. 2007;46(8):1028-40.
14. Harstad EB, Weaver AL, Katusic SK, Colligan RC, Kumar S, Chan E, et al. ADHD, stimulant treatment, and growth: a longitudinal study. Pediatrics. 2014;134(4):e935-44.

15. Schachar R, Tannock R, Cunningham C, Corkum PV. Behavioral, situational, and temporal effects of treatment of ADHD with methylphenidate. J Amer Acad Child Adol Psychiat. 1997;36:754-63.

16. Wilens TE, Faraone SV, Biederman J, Gunawardene S. Does stimulant therapy of attention-deficit/hyperactivity disorder beget later substance abuse? A meta-analytic review of the literature. Pediatrics. 2003;111(1):179-85.

17. Chang Z, Lichtenstein P, Halldner L, D'Onofrio BM, Serlachius E, Fazel S, et al. Stimulant ADHD medication and risk for substance abuse. J Child Psychol Psychiatry. 2014;55(8):878-85.

18. Groenman AP, Oosterlaan J, Rommelse NN, Franke B, Greven CU, Hoekstra PJ, et al. Stimulant treatment for attention-deficit hyperactivity disorder and risk of developing substance use disorder. Br J Psychiatry J Mental Sci. 2013;203(2):112-9.

19. Molina BS, Hinshaw SP, Eugene Arnold L, Swanson JM, Pelham WE, Hechtman L, et al. Adolescent substance use in the multimodal treatment study of attention-deficit/hyperactivity disorder (ADHD) (MTA) as a function of childhood ADHD, random assignment to childhood treatments, and subsequent medication. J Am Acad Child Adolesc Psychiatry. 2013;52(3):250-63.

20. Winhusen T, Lewis DF, Riggs PD, Davies RD, Adler LA, Sonne S, et al. Subjective effects, misuse, and adverse effects of osmoticrelease methylphenidate treatment in adolescent substance abusers with attention-deficit/hyperactivity disorder. J Child Adolescen Psychopharmacol. 2011;21:455-63.

21. Weiss M, Murray C, Wasdell M, Greenfield B, Giles L, Hechtman L. A randomized controlled trial of CBT therapy for adults with $\mathrm{ADHD}$ with and without medication. BMC Psychiatry. 2012;12(1):30.

22. Vance AL, Maruff P, Barnett R. Attention deficit hyperactivity disorder, combined type: better executive function performance with longer-term psychostimulant medication. Aust NZJ Psychiatry. 2003;37(5):570-6.

23. Semrud-Clikeman M, Pliszka S, Liotti M. Executive functioning in children with attention-deficit/hyperactivity disorder: combined type with and without a stimulant medication history. Neuropsychology. 2008;22(3):329-40.

24. Weisler R, Ginsberg L, Dirks B, Deas P, Adeyi B, Adler LA. Treatment with lisdexamfetamine dimesylate improves self- and informant-rated executive function behaviors and clinician- and informant-rated ADHD symptoms in adults: data from a randomized, double-blind, placebo-controlled study. J Atten Disord. 2014. doi: $10.1177 / 1087054713518242$.

25. Barkley RA, Edwards G, Laneri M, Fletcher K, Metevia L. Executive functioning, temporal discounting, and sense of time in adolescents with attention deficit hyperactivity disorder (ADHD) and oppositional defiant disorder (ODD). J Abnorm Child Psychol. 2001;29(6):541-56.

26. Barkley RA. Differential diagnosis of adults with ADHD: the role of executive function and self-regulation. J Clin Psychiatry. 2010;71(7):e17.

27. Hechtman L, Abikoff H, Klein RG, Weiss G, Respitz C, Kouri J, et al. Academic achievement and emotional status of children with ADHD treated with long-term methylphenidate and multimodal psychosocial treatment. J Am Acad Child Adolesc Psychiatry. 2004;43(7):812-9.

28. Abikoff H, Hechtman L, Klein RG, Weiss G, Fleiss K, Etcovitch J, et al. Symptomatic improvement in children with ADHD treated with long-term methylphenidate and multimodal psychosocial treatment. J Am Acad Child Adolesc Psychiatry. 2004;43(7):802-11.

29. Hechtman L, Abikoff H, Klein RG, Greenfield B, Etcovitch J, Cousins L, et al. Children with ADHD treated with long-term methylphenidate and multimodal psychosocial treatment: impact on 
parental practices. J Am Acad Child Adolesc Psychiatry. 2004;43(7):830-8.

30. Zoega H, Rothman KJ, Huybrechts KF, Olafsson O, Baldursson G, Almarsdottir AB, et al. A population-based study of stimulant drug treatment of ADHD and academic progress in children. Pediatrics. 2012;130(1):e53-62.

31. Scheffler RM, Brown TT, Fulton BD, Hinshaw SP, Levine P, Stone $\mathrm{S}$. Positive association between attention-deficit/ hyperactivity disorder medication use and academic achievement during elementary school. Pediatrics. 2009;123(5):1273-9.

32. Loe IM, Feldman HM. Academic and educational outcomes of children with ADHD. J Pediat Psychol. 2007;32(6):643-54.

33. Schachar R, Ickowicz A. Pharmacological treatment of ADHD. In: Quay HC, Hogan AE, editors. Handbook of disruptive behavior disorders. New York: Kluwer Academic/Plenum; 1999. p. 221-54.

34. Charach A, Ickowicz A, Schachar R. Stimulant treatment over five years: adherence, effectiveness, and adverse effects. J Am Acad Child Adolesc Psychiatry. 2004;43(5):559-67.

35. Spencer T, Biederman J, Wilens T. Growth deficits in children with attention deficit hyperactivity disorder. Pediatrics. 1998;102(2 Pt 3): 501-6.

36. Spencer TJ, Biederman J, Harding M, O’Donnell D, Faraone SV, Wilens TE. Growth deficits in ADHD children revisited: evidence for disorder-associated growth delays? J Am Acad Child Adolesc Psychiatry. 1996;35(11):1460-9.

37. Biederman J, Spencer TJ, Monuteaux MC, Faraone SV. A naturalistic 10-year prospective study of height and weight in children with attention-deficit hyperactivity disorder grown up: sex and treatment effects. J Pediatr. 2010;157(4):635-40. 640 e631.

38. Biederman J, Faraone SV, Monuteaux MC, Plunkett EA, Gifford J, Spencer T. Growth deficits and attention-deficit/hyperactivity disorder revisited: impact of gender, development, and treatment. Pediatrics. 2003;111(5 Pt 1):1010-6.

39. Faraone SV, Spencer TJ, Kollins SH, Glatt SJ. Effects of lisdexamfetamine dimesylate treatment for ADHD on growth. J Am Acad Child Adolesc Psychiatry. 2010;49(1):24-32.

40. Wilens T, McBurnett K, Stein M, Lerner M, Spencer T, Wolraich M. ADHD treatment with once-daily OROS methylphenidate: final results from a long-term open-label study. J Am Acad Child Adolesc Psychiatry. 2005;44(10):1015-23.

41. Faraone SV, Biederman J, Monuteaux M, Spencer T. Long-term effects of extended-release mixed amphetamine salts treatment of attention- deficit/hyperactivity disorder on growth. J Child Adolesc Psychopharmacol. 2005;15(2):191-202.

42. Spencer TJ, Faraone SV, Biederman J, Lerner M, Cooper KM, Zimmerman B, et al. Does prolonged therapy with a long-acting stimulant suppress growth in children with ADHD? J Am Acad Child Adolesc Psychiatry. 2006;45(5):527-37.

43. Swanson JM, Elliott GR, Greenhill LL, Wigal T, Arnold LE, Vitiello B, et al. Effects of stimulant medication on growth rates across 3 years in the MTA follow-up. J Am Acad Child Adolesc Psychiatry. 2007;46(8):1015-27.

44. Bledsoe J, Semrud-Clikeman M, Pliszka SR. A magnetic resonance imaging study of the cerebellar vermis in chronically treated and treatment-naïve children with attention-deficit/hyperactivity disorder combined type. Biol Psychiatry. 2009;65(7):620-4.

45. Castellanos FX, Lee PP, Sharp W, Jeffries NO, Greenstein DK, Clasen LS, et al. Developmental trajectories of brain volume abnormalities in children and adolescents with attention-deficit/hyperactivity disorder. JAMA. 2002;288(14):1740-8.

46. Pliszka SR, Lancaster J, Liotti M, Semrud-Clikeman M. Volumetric MRI differences in treatment-naïve vs chronically treated children with ADHD. Neurology. 2006;67(6):1023-7.

47. Schnoebelen S, Semrud-Clikeman M, Pliszka SR. Corpus callosum anatomy in chronically treated and stimulant naïve ADHD. J Atten Disord. 2010;14(3):256-66.
48. Sobel LJ, Bansal R, Maia TV, Sanchez J, Mazzone L, Durkin K, et al. Basal ganglia surface morphology and the effects of stimulant medications in youth with attention deficit hyperactivity disorder. Am J Psychiatry. 2010;167(8):977-86.

49. Shaw P, Sharp WS, Morrison M, Eckstrand K, Greenstein DK, Clasen LS, et al. Psychostimulant treatment and the developing cortex in attention deficit hyperactivity disorder. Am J Psychiatry. 2009;166(1):58-63.

50. Frodl T, Skokauskas N. Meta-analysis of structural MRI studies in children and adults with attention deficit hyperactivity disorder indicates treatment effects. Acta Psychiatr Scand. 2012;125(2):114 26.

51. Spencer TJ, Brown A, Seidman LJ, Valera EM, Makris N, Lomedico A, et al. Effect of psychostimulants on brain structure and function in ADHD: a qualitative literature review of magnetic resonance imaging-based neuroimaging studies. J Clin Psychiatry. 2013;74(9):902-17.

52. Wehmeier PM, Schacht A, Barkley RA. Social and emotional impairment in children and adolescents with ADHD and the impact on quality of life. J Adolescent Health. 2010;46(3):209-17.

53. Klassen AF, Miller A, Fine S. Agreement between parent and child report of quality of life in children with attention-deficit/hyperactivity disorder. Child Care Health Dev. 2006;32(4):397-406.

54. Rajmil L, Estrada MD, Herdman M, Serra-Sutton V, Tebe C, Izaguirre J, et al. Parent-child agreement in the health related quality of life (HRQOL) of children with attention-deficit/hyperactivity disorder (ADHD): a longitudinal study. Anal Pediatr. 2009;70(6): 553-61.

55. Owens JS, Goldfine ME, Evangelista NM, Hoza B, Kaiser NM. A critical review of self-perceptions and the positive illusory bias in children with ADHD. Clin Child Fam Psychol Rev. 2007;10(4): $335-51$.

56. Volz-Sidiropoulou E, Boecker M, Gauggel S. The positive illusory bias in children and adolescents with ADHD: further evidence. $\mathrm{J}$ Atten Disord. 2013. doi:10.1177/1087054713489849.

57. Klassen AF, Miller A, Fine S. Health-related quality of life in children and adolescents who have a diagnosis of attention-deficit/hyperactivity disorder. Pediatrics. 2004;114(5):e541-7.

58. Frazier TW, Weiss M, Hodgkins P, Manos MJ, Landgraf JM, Gibbins C. Time course and predictors of health-related quality of life improvement and medication satisfaction in children diagnosed with attention-deficit/hyperactivity disorder treated with the methylphenidate transdermal system. J Child Adolesc Psychopharmacol. 2010;20(5):355-64.

59. Weiss MD, Gibbins C, Goodman DW, Hodgkins PS, Landgraf JM, Faraone SV. Moderators and mediators of symptoms and quality of life outcomes in an open-label study of adults treated for attentiondeficit/hyperactivity disorder. J Clin Psychiatry. 2010;71(4):38190.

60. Manos M, Frazier TW, Landgraf JM, Weiss M, Hodgkins P. HRQL and medication satisfaction in children with ADHD treated with the methylphenidate transdermal system. Curr Med Res Opin. 2009;25(12):3001-10.

61. Spencer TJ, Landgraf JM, Adler LA, Weisler RH, Anderson CS, Youcha SH. Attention-deficit/hyperactivity disorder-specific quality of life with triple-bead mixed amphetamine salts (SPD465) in adults: results of a randomized, double-blind, placebo-controlled study. J Clin Psychiatry. 2008;69(11):1766-75.

62. Goetz M, Yeh CB, Ondrejka I, Akay A, Herczeg I, Dobrescu I, et al. A 12-month prospective, observational study of treatment regimen and quality of life associated with ADHD in central and eastern Europe and eastern Asia. J Atten Disord. 2012;16(1):44-59.

63. Charach A, Yeung E, Volpe T, Goodale T, Dosreis S. Exploring stimulant treatment in ADHD: narratives of young adolescents and their parents. BMC Psychiatry. 2014;14:110. 
64. Fuentes J, Danckaerts M, Cardo E, Puvanendran K, Berquin P, De Bruyckere $\mathrm{K}$, et al. Long-term quality-of-life and functioning comparison of atomoxetine versus other standard treatment in pediatric attention-deficit/hyperactivity disorder. J Clin Psychopharmacol. 2013;33(6):766-74.

65. Jensen PS, Arnold LE, Swanson JM, Vitiello B, Abikoff HB, Greenhill LL, et al. 3-year follow-up of the NIMH MTA study. J Am Acad Child Adolesc Psychiatry. 2007;46(8):989-1002.

66. Parker J, Wales G, Chalhoub N, Harpin V. The long-term outcomes of interventions for the management of attention-deficit hyperactivity disorder in children and adolescents: a systematic review of randomized controlled trials. Psychol Res Behav Manag. 2013;6. An excellent review and interpretation of long term outcome of $R C T$ studies.

67. Swanson J, Arnold LE, Kraemer H, Hechtman L, Molina B, Hinshaw S, et al. Evidence, interpretation, and qualification from multiple reports of long-term outcomes in the Multimodal Treatment Study of children with ADHD (MTA): supporting details. J Atten Disord. 2008;12(1):4-43.

68. Weiss MD, Worling DE, Wasdell MB. A chart review study of the inattentive and combined types of ADHD. J Atten Disord. 2003;7(1):1-9. 